\title{
Computer Aided Design and Performance Analysis of Inverse Fluidized Bed Biofilm Reactors with Special Reference to Bioplastic Synthesis*
}

\author{
C. M. Narayanan, Shrijita Das \\ Department of Chemical Engineering, National Institute of Technology, Durgapur, India \\ Email:cmn_recd@yahoo.co.in,shrijita.das92@gmail.com
}

Received 3 March 2016; accepted 12 April 2016; published 15 April 2016

Copyright (C) 2016 by authors and Scientific Research Publishing Inc.

This work is licensed under the Creative Commons Attribution International License (CC BY).

http://creativecommons.org/licenses/by/4.0/

(c) () Open Access

\section{Abstract}

Poly Laevo Lactic Acid (PLLA), in spite of being an excellent bioplastic, has exorbitantly high market price due to the high cost of raw material (lactose, glucose, sucrose). Hence, its manufacture is being attempted starting from waste effluents such as cheese whey and molasses. Earlier studies on the same in fluidized bed and semifluidized bed biofilm reactors yielded encouraging results. The present study therefore involves design and analysis of inverse fluidized bed biofilm reactors for lactic acid synthesis. The performance features of the bioreactor have been studied both mathematically as well as experimentally. The inverse fluidized bed biofilm reactor has been found to provide more than $\mathbf{7 5 \%}$ conversion of sucrose/lactose even at high capacities (high feed flow rates) exceeding 56,000 $\mathrm{L} / \mathrm{hr}$, within a reasonably low reactor volume. The fractional substrate conversion increases, though sluggishly, with increase in feed flow rate due to bed expansion and also with increase in cell mass concentration in biofilm due to enhancement in intrinsic rate of bioconversion. The inverse fluidized bed biofilm reactor of proposed design could be safely recommended for the commercial synthesis of polymer grade lactic acid from waste effluents such as cheese whey and molasses. The low operating cost of the bioreactor (due to downflow mode of operation) enhances the economy of the process. This would also help in significantly lowering the market price of the green plastic (PLLA) and shall promote its large scale manufacture and utilisation.

\section{Keywords}

Inverse Fluidized Bed Biofilm Reactors, Computer Aided Design, Bioplastics, Lactic Acid Synthesis, Software Development

"Paper presented in the ISHMT-ASTFE International Heat and Mass Transfer Conference held at Trivandrum, India during December 17-20 2015.

How to cite this paper: Narayanan, C.M. and Das, S. (2016) Computer Aided Design and Performance Analysis of Inverse Fluidized Bed Biofilm Reactors with Special Reference to Bioplastic Synthesis. Advances in Chemical Engineering and Science, 6, 130-139. http://dx.doi.org/10.4236/aces.2016.62015 


\section{Introduction}

Inverse fluidization technology is not a new concept, though the application of this technology to the design of bioreactors has been investigated only during the recent past. In the most conventional design, inverse fluidized beds are composed of particles that are of lower density than the liquid (feed solution). Consequently, though the liquid is fed from the top and executes downflow, these particles remain suspended in the descending stream of liquid and thus form a fluidised bed. In the present study, particles made of polymer composites (that are lighter than water) each surrounded by a biofilm (a thin film of microbial solution) are used and these particle-biofilm aggregates remain fluidised in the down-flowing substrate solution (feed solution).

Studies on hydrodynamic characteristics of liquid-solid inverse fluidised beds have been reported by Ulaganathan and Krishnaiah [1] and Banerjee, Basu and Ganguly [2]. Both of these investigators have considered flow of Newtonian fluids (water and aqueous solutions) through inverse fluidised beds composed of polymer beads and granules. Non-Newtonian flow (flow of CMC-carboxy methyl cellulose-solutions) in inverse fluidized beds has been analysed Vijayalakshmi [3] et al. For the estimation of minimum inverse fluidization velocity, $U_{m f}(i n v)$, a modified form of the correlation proposed by Ulaganathan and Krishnaiah [1] has been used in the present study:

$$
U_{m f}(\text { inv })=2.93 \times 10^{-3} A r^{0.202}\left[\left(\rho_{L}-\rho_{S m}\right) / \rho_{L}\right]^{0.38}
$$

where,

$$
\begin{gathered}
A r=\left(\rho_{L}-\rho_{s m}\right) g d_{P m}^{3} \rho_{L} / \mu_{L}^{2} \\
\rho_{S m}=f \rho_{L}+(1-f) \rho_{S} \\
f=1-\left(d_{P}^{3} / d_{P m}^{3}\right) \\
d_{P m}=d_{P}+2 \delta
\end{gathered}
$$

$\delta=$ biofilm thickness (assumed constant).

In the above equations, $\rho_{S m}$ and $d_{P m}$ are density and effective size respectively of particle-biofilm aggregates and $\mathrm{Ar}$ is the modified Archemedes number. The parameter $f$ represents the volume fraction of biofilm in particle-biofilm aggregate. The above correlation is valid for $10^{6}<\mathrm{Ar}<7 \times 10^{7}$ and $0.4<\left(\rho_{L}-\rho_{S m}\right) / \rho_{L}<0.9$. The operating velocity of the feed solution, $U_{L}$, is then chosen as at least $20 \%$ higher than this minimum.

The above authors [1] have also proposed a correlation for the estimation of expanded bed height $\left(L_{f}\right)$.

$$
L_{f} / L_{S}=(0.572) \operatorname{Re}^{0.92} A r^{-0.345}\left[\left(\rho_{L}-\rho_{S m}\right) / \rho_{L}\right]^{-0.21}
$$

where,

$$
R e=d_{P m} \rho_{L} U_{L} / \mu_{L} .
$$

The voidage of the bed, $\varepsilon_{f}$ (which is equal to the fractional liquid holdup, $\varepsilon_{f L}$ ) could be then estimated from a solid balance as

$$
\varepsilon_{f}=1-\left[L_{S} / L_{f}\right]\left(1-\varepsilon_{P}\right)
$$

where $\varepsilon_{P}$ is the voidage of the original static bed (of height, $L_{S}$ ).

As stated earlier, reported studies on design and analysis of inverse fluidised bed bioreactors are scarce in literature. Performance characteristics of immobilized enzyme inverse fluidized bed bioreactors of modified design that employ nanosilica particles as support media have been analysed by Narayanan [4] et al. The superior performance features of such reactors have been effectively highlighted by these authors.

The specific process considered in the present study is synthesis of lactic acid from molasses and cheese whey. Lactic acid is the starting material for the manufacture of PLLA (Poly Laevo Lactic Acid) which is the most promising bioplastic (green plastic) in the present context. Lactic acid synthesis from pure lactose, glucose or sucrose is exhorbitantly expensive and hence cannot be recommended for the commercial manufacture of PLLA. 
We have therefore selected molasses and cheese whey as the starting materials which are waste effluents discharged from cane sugar manufacturing industries and milk processing plants and thus are available practically free of cost. Our earlier investigations [5]-[7] have successfully demonstrated that these two are promising raw materials for commercial manufacture of polymer grade lactic acid in fluidised bed biofilm reactors [5], in semifluidized bed biofilm reactors [6] and in fluidised bed biofilm reactors of diverging-converging geometry [7]. In the present project, design and analysis of inverse fluidised bed bioreactors have been attempted for lactic acid synthesis from molasses and cheese whey permeate (the permeate left behind after the separation of proteins from raw cheese whey by ultrafiltration).

\section{Mathematical Modeling}

A schematic view of Inverse fluidised bed biofilm reactor is shown in Figure 1. Assuming dispersed flow of substrate solution through the reactor column, the performance equation for the bioreactor is,

$$
\left(-U_{L} / \varepsilon_{f}\right)\left(\mathrm{d} C_{S} / \mathrm{d} z\right)+D_{L f}\left(\mathrm{~d}^{2} C_{S} / \mathrm{d} z^{2}\right)=\eta\left(-r_{S}\right)(i n t)
$$

where, $U_{L}=$ operating superficial velocity of feed solution (selected as at least $20 \%$ higher than the minimum, as stated earlier)

$$
=Q_{0} /\left(\pi D^{2} / 4\right) .
$$

$Q_{O}=$ volumetric flow rate of feed solution employed, $\mathrm{m}^{3} / \mathrm{s}$.

$D_{L f}=$ axial dispersion coefficient, $\mathrm{m}^{2} / \mathrm{s}$.

$\eta$ = effectiveness factor, dimensionless.

$\left(-r_{S}\right)($ int $)=$ intrinsic rate of bioconversion of sucrose/lactose, g/(L.s).

In the case of sucrose from molasses being fermented to lactic acid using Enterococcus faecalis as biocatalyst or lactose from cheese whey being fermented to lactic acid using Lactobacillus helveticus as biocatalyst, the intrinsic kinetics of bioconversion follows Monod-type kinetic equation. Thus,

$$
\begin{aligned}
\left(-r_{S}\right)(\text { int }) & =\mu_{m}(\text { app }) C_{S} /\left(K_{S}+C_{S}\right) \\
\text { where, } \mu_{m}(\text { app }) & =\left(\mu_{m} / Y\right)\left(x_{f} f\right)\left(1-\varepsilon_{f}\right) / \varepsilon_{f}
\end{aligned}
$$

$x_{f}=$ biomass concentration in the biofilm (assumed constant).

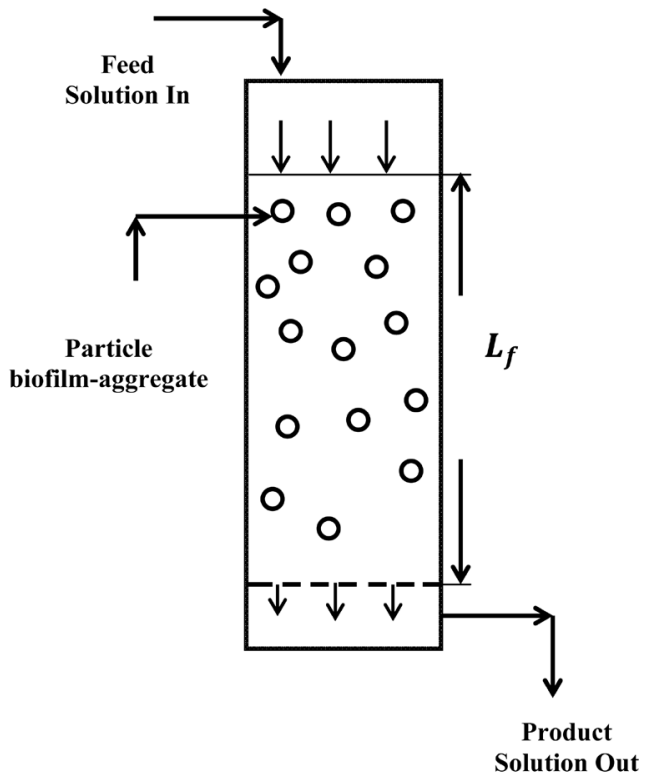

Figure 1. A schematic diagram of inverse fluidized bed bioreactor. 
$Y=$ overall yield coefficient for cell mass production.

The values of kinetic constants reported by Anjana and Kumar [8] for lactic acid synthesis from molasses are, $\left(\mu_{m} / Y\right)=3.33 \mathrm{hr}^{-1}$ and $K_{s}=0.1 \mathrm{~g} / \mathrm{L}$.

In case of lactic acid synthesis from cheese whey permeate using a microbial culture of Lactobacillus helveticus, the kinetic constants reported by Schepers [9] et al. are, $\mu_{m}=0.7 \mathrm{hr}^{-1}, K_{s}=0.22 \mathrm{~g} / \mathrm{L}, \quad Y=0.65$.

All the above values of kinetic constants have been verified experimentally by us and then utilised in the present analysis.

The parameters $\left(\delta, x_{f}\right)$ have been assumed to remain more or less unaltered during the entire period of operation of the bioreactor. This, in fact, is a well-justified assumption. Cell growth and multiplication do take place in the biofilm. And so are cell death or cell decay. However, as the biomass concentration exceeds a particular value, the biofilm gets detached from the particle surface (the phenomenon being known as sloughing) and it gets replenished immediately by a new layer of microbial cells. Also, as dead cells fall out from the biofilm, they are at once replaced by living cells. As a consequence, both the biofilm thickness $(\delta)$ as well as the biomass concentration in the biofilm $\left(x_{f}\right)$ remain more or less constant during the entire operation of the bioreactor.

It is also to be noted that due to the high magnitude of cell mass concentration in the biofilm (the value of $x_{f}$ often exceeds 5 - 10 times the substrate concentration in the feed solution), the rate of bio-conversion attained shall also be substantially large.

The effectiveness factor $(\eta)$ is computed from the correlation proposed by Gottifreddi and Gonzo [10]:

$$
(1 / \eta)^{2}=\left(1 / \eta_{d}\right)^{2}+\exp \left[6\left(\varphi^{\prime}\right)^{2} /\left\{5(1+\beta)^{2}\right\}-\left(1 / \eta_{d}\right)^{2}\right]
$$

where,

$$
\begin{aligned}
& \eta_{d}=\left(\sqrt{2} / \varphi^{\prime}\right)[(1+\beta) / \beta]\{\beta-\ln (1+\beta)\}^{1 / 2} \\
& \varphi^{\prime}=\left(L_{P} / 6\right)\left[\mu_{m}(a p p) / D_{e} K_{S}\right]^{1 / 2} \\
& \beta=\left(C_{S P} / K_{S}\right) \\
& L_{P}=\text { characteristic dimension } \\
& =(\text { volume of biofilm }) /(\text { surface area of biofilm }) \\
& =\left(d_{P m}^{3}-d_{P}^{3}\right) / 6 d_{P m}^{2}
\end{aligned}
$$

$D_{e}=$ effective diffusivity of substrate into biofilm.

The substrate concentration at the biofilm surface (at the liquid-biofilm interface), namely $C_{S P}$, depends on the rate of substrate transfer from the liquid bulk to the biofilm surface. However, due to the large degree of turbulence in the fluidized bed, the liquid to particle mass transfer coefficient has been observed to be significantly large. As a result, without any serious error, it could be assumed that substrate concentration (sucrose concentration/lactose concentration) at the liquid-biofilm interface $\left(C_{S P}\right)$ is more or less equal to that in the liquid bulk at any cross-section of the bioreactor $\left(C_{S}\right)$. In other words, in the case of the bioreactor under consideration, we may safely assume that:

$$
C_{S P} \approx C_{S} \text {. }
$$

Computation of effectiveness factor $(\eta)$ from the above equations, Equations (12) to (15), has been performed based on the above assumption. An experimental value of axial dispersion coefficient $\left(D_{L f}=0.03125 \mathrm{~m}^{2} / \mathrm{s}\right.$ ) is used in computations.

Equation (9) is solved numerically using a modified form of Runge-Kutta method starting from the bottom 
(where $z=0, C_{S}=C_{S e}$ ). Computations were continued upward until $C_{S}=C_{S O}$ and $z=L_{f}$. The fractional conversion of sucrose/lactose is then given by:

$$
\alpha=\left(C_{S O}-C_{S e}\right) / C_{S O} .
$$

The software package is re-executed at different values of feed flow rate $\left(Q_{O}\right)$ and at different $C_{S e}$-values. In each case, the fractional substrate conversion $(\alpha)$ attained and the required height of reactor column $\left(L_{f}\right)$ are computed. Typical results are illustrated graphically in Figures 2-6.

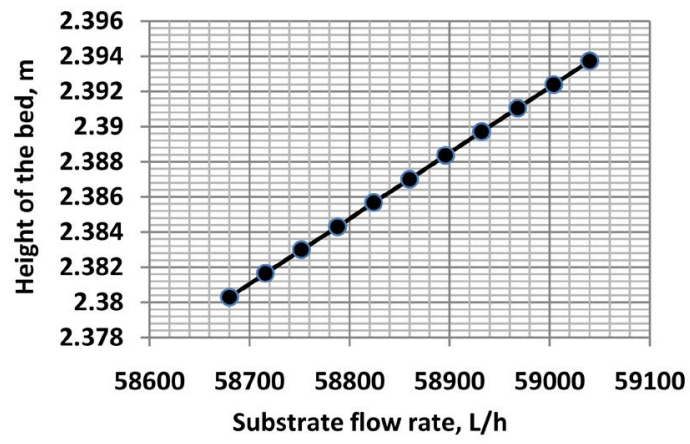

Figure 2. Variation of height of the fluidised bed $\left(L_{f}\right)$ with substrate flow rate $\left(Q_{O}\right)$. Feed solution = molasses, $\quad d_{P}=12.5 \mathrm{~mm}, \quad x_{f}=500 \mathrm{~g} / \mathrm{L}$.

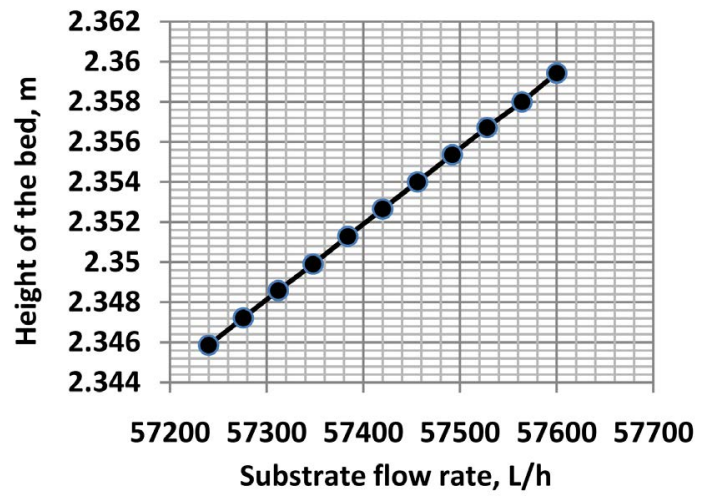

Figure 3. Variation of height of the fluidised bed $\left(L_{f}\right)$ with substrate flow rate $\left(Q_{O}\right)$. Feed solution $=$ molasses $, d_{P}=12 \mathrm{~mm}, x_{f}=500 \mathrm{~g} / \mathrm{L}$.

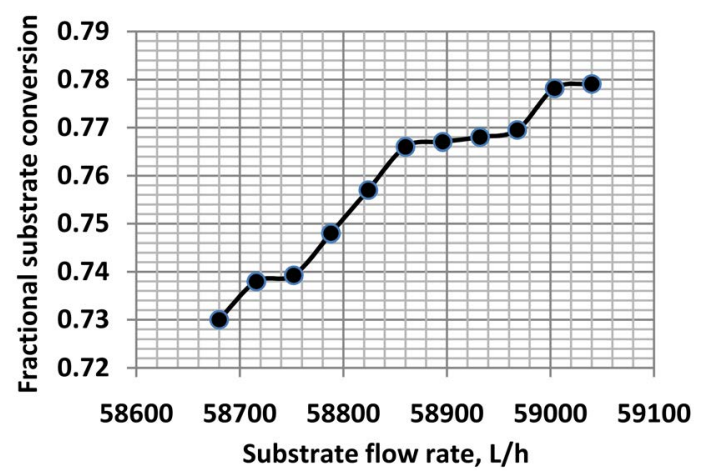

Figure 4. Variation of fractional substrate conversion $(\alpha)$ with substrate flow rate $\left(Q_{O}\right)$. Feed solution = molasses, $d_{P}=12.5 \mathrm{~mm}, \quad x_{f}=500 \mathrm{~g} / \mathrm{L}$. 


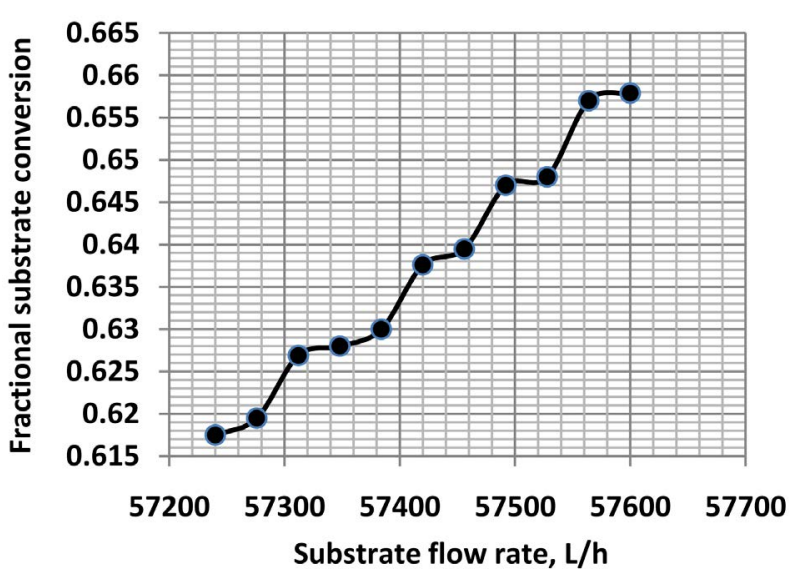

Figure 5. Variation of fractional substrate conversion $(\alpha)$ with substrate flow rate $\left(Q_{O}\right)$. Feed
solution = molasses, $d_{P}=12 \mathrm{~mm}, x_{f}=500 \mathrm{~g} / \mathrm{L}$.

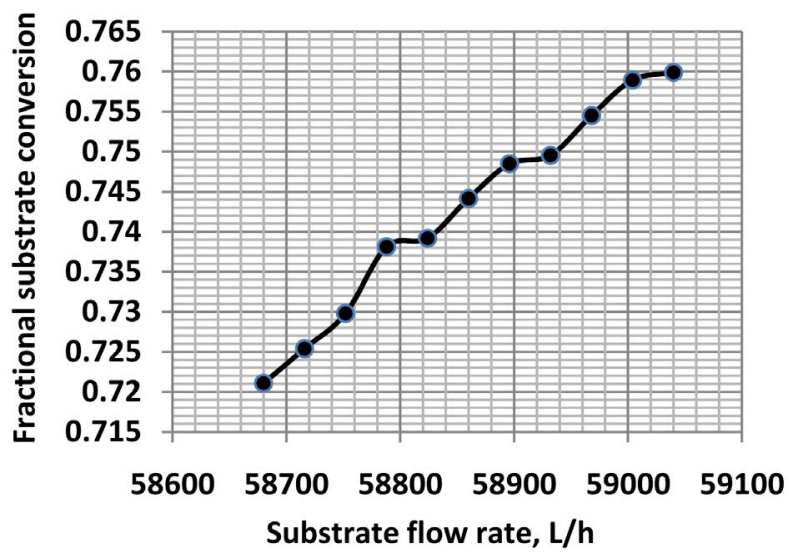

Figure 6. Variation of fractional substrate conversion $(\alpha)$ with substrate flow rate $\left(Q_{O}\right)$. Feed solution $=$ cheese whey permeate, $d_{p}=12.5 \mathrm{~mm}, \quad x_{f}=150 \mathrm{~g} / \mathrm{L}$.

\section{Experimental Study}

The purpose of experimental work was to test the accuracy and reliability of the software package developed (described above). For this, the numerical values of system/operating parameters (expanded bed height, fractional substrate conversion) computed using the developed CAD software were compared against the experimental data complied on pilot plant scale. Out of 25 data points collected on a pilot plant bioreactor $0.5 \mathrm{~m}$ in diameter, $1.5 \mathrm{~m}$ height, composed of PP composite beads each surrounded by $0.3 \mathrm{~mm}$ biofilm, with clarified molasses as feedstock, 15 of them deviated by 12\% (max) from the results ( $\alpha$-values) computed from the developed software package and the remaining deviated by less than $10 \%$. With cheese whey as charge stock (cheese whey collected from dairy farms was subjected to ultrafiltration, after preliminary treatments, to separate all the milk proteins and the UF permeate is then used as the feedstock for lactic acid synthesis), the computed values and the experimental values of $\alpha$ deviated by 15\% (max) and 5\% (min). The developed software could be thus treated as reasonably accurate and reliable.

The biomass concentration in the biofilm $\left(x_{f}\right)$ was maintained at $500 \mathrm{~g} / \mathrm{L}$ during experiments with clarified molasses as the feed solution and a value of $x_{f}=100 \mathrm{~g} / \mathrm{L}$ is employed when experiments were conducted using cheese whey permeate as the substrate. Concentration measurements were performed using a spectrophotometer (at $600 \mathrm{~nm}$ wave length) and HPLC (High pressure Liquid Chromatograph, Agilent Technologies 1200 series, CA, USA). Readings were repeated three to four times at each flow rate to ascertain the experimental accuracy. 


\section{Results and Discussion}

Two typical plots of expanded bed height versus feed flow rate $\left(Q_{O}\right)$ are shown in Figure 2 and Figure 3. Within the range of feed flow rate handled, the increase in $L_{f}$ with increase in liquid flow rate is not large ( $L_{f}$ varies within 2.35 to $2.5 \mathrm{~m}$ ). This is true for all the three particle sizes considered. ( $d_{P}=11 \mathrm{~mm}, 12 \mathrm{~mm}, 12.5$ $\mathrm{mm})$. The variation, however, is close to linear.

\subsection{Effect of Feed Flow Rate on Reactor Performance}

The dependence of fractional conversion of sucrose/lactose attained on feed flow rate ( $\alpha$ versus $Q_{O}$ ) is illustrated in Figures 4-7. Figure 4 and Figure 5 are for fermentation of molasses with $x_{f}=500 \mathrm{~g} / \mathrm{L}$ (cell mass concentration in biofilm being maintain constant at $500 \mathrm{~g} / \mathrm{L}$ ) and for different support particle sizes such as $d_{P}$ $=12 \mathrm{~mm}, 12.5 \mathrm{~mm}$. The biofilm thickness remains the same $(\delta=0.3 \mathrm{~mm})$ for particles of all sizes. It can be seen that the bioreactor provides more than $75 \%$ conversion of sucrose at feed flow rates exceeding $55,000 \mathrm{~L} / \mathrm{hr}$ when the particle size $\left(d_{p}\right)$ employed is $12.5 \mathrm{~mm}$. With $12 \mathrm{~mm}$ particles, the conversion attained is slightly lower (though more than 65\%) at comparable flow rates. As stated earlier, the expanded height of the bed (effective height of reactor column) is less than $2.5 \mathrm{~m}$, the column diameter being $0.5 \mathrm{~m}$. It can be thus inferred that this bioreactor is capable of providing large degree of bioconversion (large yield of lactic acid) within a low reactor volume. The fractional substrate conversion attained is higher at larger particle size.

The observation is exactly similar in the case of fermentation of cheese whey permeate as well (Figure 6 and Figure 7). Here also, the fractional conversion of lactose (to lactic acid) attained is more than $75 \%$ even at large feed flow rates (more than 56,000 L/hr) when $d_{P}=12.5 \mathrm{~mm}$. No doubt, $\alpha$ (attained) is lower at lower particle size $\left(d_{P}=12 \mathrm{~mm}\right)$. The cell mass concentration maintained in the biofilm $\left(x_{f}\right)$ in this case is $150 \mathrm{~g} / \mathrm{L}$. To note that lactose concentration in the cheese whey permeate (feed solution) is $9.0 \mathrm{~g} / \mathrm{L}$, while $C_{S O}=$ sucrose concentration in feed molasses $=150 \mathrm{~g} / \mathrm{L}$.

The magnitude of $\alpha$ (attained) does increase, but sluggishly, with increase in $Q_{O}$, as can be seen from Figures 4-7. This is due to the increase in expanded bed height $\left(L_{f}\right)$ and a simultaneous increase in $\varepsilon_{f}$ (bed voidage).

\subsection{Effect of Cell Mass Concentration in Biofilm on Reactor Performance}

Figure 8 effectively demonstrates that a large value of cell mass concentration in biofilm $\left(x_{f}\right)$ helps in attaining larger degree of substrate (here, sucrose) conversion at any selected feed flow rate $\left(Q_{O}\right)$. The situation is analogous with lactose fermentation as well (Figure 9). Though the plots shown are for $d_{P}=12 \mathrm{~mm}$, the phenomenon has been observed to be identical at all particle sizes considered. This observation is not surprising, since larger the biomass concentration, larger shall be the intrinsic rate of bioconversion, $\left(-r_{S}\right)($ int $)$, as is

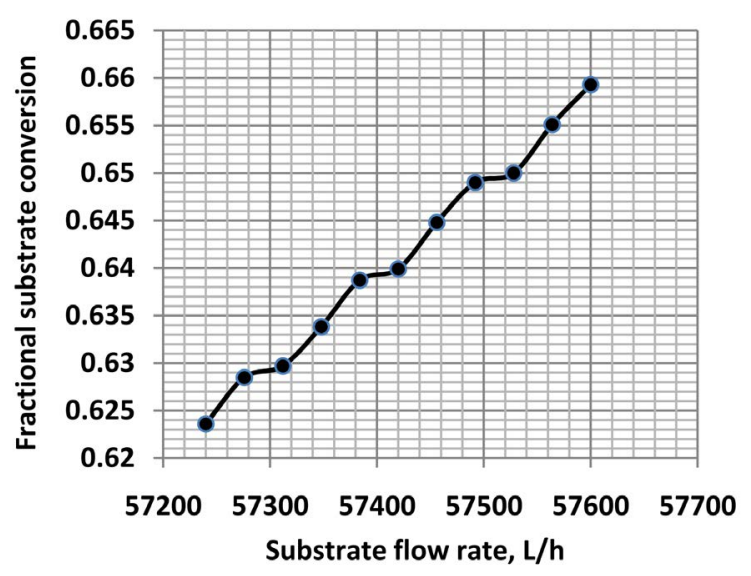

Figure 7. Variation of fractional substrate conversion $(\alpha)$ with substrate flow rate $\left(Q_{O}\right)$. Feed solution $=$ cheese whey permeate, $d_{p}=12 \mathrm{~mm}, x_{f}=150 \mathrm{~g} / \mathrm{L}$. 


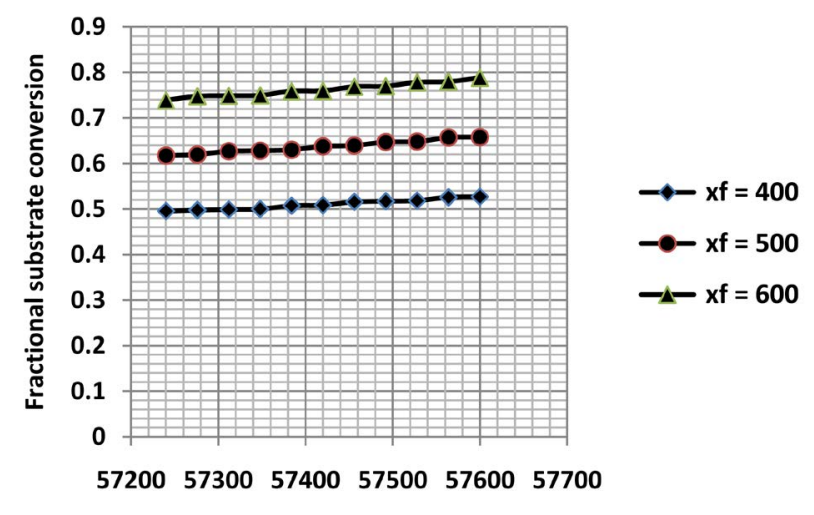

Substrate flow rate, $\mathrm{L} / \mathrm{h}$

Figure 8. Variation of fractional substrate conversion $(\alpha)$ with substrate flow rate $\left(Q_{O}\right)$ at dif-
ferent values of biomass concentration in biofilm $\left(x_{f}\right)$. Feed solution = molasses, $d_{P}=12 \mathrm{~mm}$.

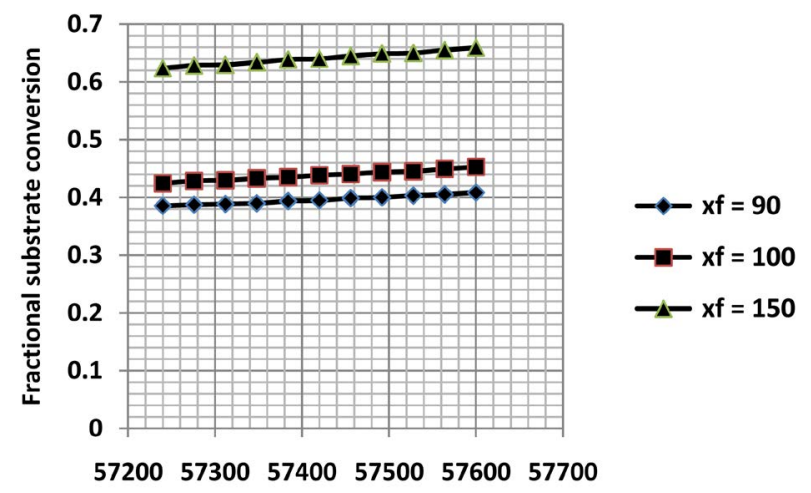

Substrate flow rate, $\mathrm{L} / \mathrm{h}$

Figure 9. Variation of fractional substrate conversion $(\alpha)$ with substrate flow rate $\left(Q_{O}\right)$ at different values of biomass concentration in biofilm $\left(x_{f}\right)$. Feed solution = cheese whey permeate, $d_{P}=12 \mathrm{~mm}$.

evident from Equations (11) and (12). However, too large biomass concentration in the film could make the biofilm unstable and it shall have pronounced tendency to get detached from the particle surface.

\subsection{Operating Cost of Bioreactor}

The downflow mode of operation is another exquisite advantage of inverse fluidized bed bioreactors. This brings down the operating cost of the reactor as compared to the conventional fluidized bed/semifluidized bed reactors where the fluid is to be pumped upward. Another advantage due to the downflow mode of operation is that problems related to entrainment of particles or particle-biofilm aggregates in the outgoing product solution are absent in bioreactors of this category.

\section{Conclusions}

1) Performance characteristics of inverse fluidized bed biofilm reactors are analysed with special reference to synthesis of polymer grade lactic acid from waste effluents such as molasses and cheese whey.

2) A multi-parameter software package has been developed which predicts the performance of the bioreactor satisfactorily. The reliability of the package has been verified by comparing with pilot plant data.

3) This bioreactor provides more than $75 \%$ conversion of sucrose/lactose within a reactor height of $2.4 \mathrm{~m}$ at large feed flow rates (large capacities) exceeding 56,000 L/hr. 
4) The fractional substrate conversion does increase with increase in cell mass concentration in the biofilm, though large values of $x_{f}$ are difficult to maintain in industrial bioreactors.

5) Since the feed solution is not required to be pumped upward and it executes downflow under gravity, the operating cost of this bioreactor is lower than that of fluidized bed/semifluidized bed bioreactors which handle an ascending stream of fluid. This downflow mode of operation also inhibits entrainment loss of particles in the product solution discharged.

6) This bioreactor also permits use of large size support particles and thus larger size particle-biofilm aggregates, though the particle material must be so chosen that its density is sufficiently lower than the substrate solution handled.

\section{Future Research Areas}

At large liquid velocities, the particles experience large hydrodynamic forces and as a result, these particles could have a tendency to aggregate (or accumulate) at the bottom of the column, just above the bottom porous plate and thereby tend to form a compact packed bed there (similar to what occurs in a semifluidized bed). Such a rearrangement of particles, if occurs, could very much affect the overall performance of the reactor. More elaborate studies are required to throw more light on this feasible phenomenon.

\section{Acknowledgements}

We are grateful to all the fellow members of our International Research Group and to a number of consultancy firms of India whose assistances were invaluable for the successful completion of this project.

\section{References}

[1] Ulaganathan, N. and Krishnaiah, K. (1996) Hydrodynamic Characteristics of Two-Phase Inverse Fluidized Bed. Bioprocess Engineering, 15, 159-164. http://dx.doi.org/10.1007/bf00369620

[2] Banerjee, J., Basu, J.K. and Ganguly, U.P. (1999) Some Studies on the Hydrodynamics of Reverse Fluidization Velocities. Ind. Chem. Engr., 41, 35-38.

[3] Vijayalakshmi, A.C., Balamurugan, M., Sivakumar, M., Newton, T.S. and Velan, M. (2000) Minimum Fluidization Velocity and Friction Factor in a Liquid-Solid Inverse Fluidized Bed Reactor. Bioprocess Engineering, 22, 461-466. http://dx.doi.org/10.1007/s004490050759

[4] Narayanan, C.M., Tejaswi, M., Prasad, H. and Chakraborty, N. (2014) Studies on Performance Analysis and Computer Aided Design of Inverse Fluidized Bed Bioreactors with Nano-Support Particles. International Journal of Chemical Reactor Engineering, 12, 303-315. http://dx.doi.org/10.1515/ijcre-2014-0027

[5] Narayanan, C.M. (2015) Case Studies on Synthesis of PLLA Bioplastic Starting from Food and Agricultural Wastes. Int. J. Chem. Eng. Processing, 1, 1-13.

[6] Narayanan, C.M. and Das, S. (2015) Studies on Synthesis of Lactic Acid from Molasses and Cheese Whey in Semifluidized Bed Biofilm Reactors. Proc. Golden Jubilee Int. Conf. Recent Dev. in Chem. and Biochem. Eng., NIT Durgapur.

[7] Narayanan, C.M., Basak, A., Saha, A. and Jha, S. (2014) Studies on Performance Characteristics of Diverging-Converging Fluidized Bed Biofilm Reactor with Special Reference to Lactic Acid Synthesis from Molasses and Cheese Whey. International Review of Chemical Engineering, 6, 142-152.

[8] Anjana, D.N. and Kumar, S. (2008) Kinetic Modelling of Lactic Acid Production from Molasses Using Enterococcus faecalis RKY1. Biochemical Engineering Journal, 38, 277-284. http://dx.doi.org/10.1016/j.bej.2007.07.014

[9] Schepers, A.W., Thibault, J. and Lacroix, C. (2002) Lactobacillus helveticus Growth and Lactic Acid Production during pH-Controlled Batch Cultures in Whey Permeate/Yeast Extract Medium. Part-I. Multiple Factor Kinetic Analysis. Enzyme and Microbial Technology, 30, 176-186. http://dx.doi.org/10.1016/S0141-0229(01)00465-3

[10] Gottifredi, J.C. and Gonzo, E.E. (2005) An Approximate Expression for Estimation of Effectiveness Factor. Chemical Engineering Journal, 109, 83-85. http://dx.doi.org/10.1016/j.cej.2005.03.012 


\section{Nomenclatures}

Ar modified Archemedes number.

$C_{S e}$ substrate concentration in product solution, g/L.

$C_{S O}$ substrate concentration in feed solution, g/L.

$d_{P}$ diameter of support particle, $\mathrm{m}$.

$d_{P m}$ diameter of particle-biofilm aggregate, $\mathrm{m}$.

$D_{e}$ effective diffusivity of substrate into biofilm, $\mathrm{m}^{2} / \mathrm{s}$.

$D_{L f}$ axial dispersion coefficient, $\mathrm{m}^{2} / \mathrm{s}$.

$f$ volume fraction of biofilm in particle-biofilm aggregate, dimensionless.

$K_{S}$ Monod's kinetic constant, g/L.

$L_{f}$ height of fluidised bed, $\mathrm{m}$.

$L_{P} \quad$ characteristic dimension, $\mathrm{m}$.

$L_{S}$ height of original static bed, $\mathrm{m}$.

$Q_{O}$ substrate flow rate, $\mathrm{L} / \mathrm{h}$.

Re modified Reynolds number.

$\left(-r_{S}\right)($ int $)$ intrinsic rate of bioconversion, g/(L.s).

$U_{L}$ superficial velocity of liquid, $\mathrm{m} / \mathrm{s}$.

$U_{m f}(i n v)$ minimum inverse fluidization velocity, $\mathrm{m} / \mathrm{s}$.

$x_{f}$ biomass concentration in biofilm, g/L.

$Y$ overall yield coefficient, $\mathrm{mg} / \mathrm{mg}$.

$\alpha$ fractional conversion, dimensionless.

$\delta$ biofilm thickness, m.

$\varepsilon_{f}$ total voidage (=liquid holdup) of fluidised bed.

$\varepsilon_{P}$ total voidage (=liquid holdup) of original static bed.

$\eta$ effectiveness factor, dimensionless.

$\mu_{m}$ maximum specific growth rate, $\mathrm{s}^{-1}$.

$\mu_{L}$ viscosity of fluid, $\mathrm{kg} / \mathrm{m} \cdot \mathrm{s}$.

$\rho_{L}$ density of fluid, $\mathrm{kg} / \mathrm{m}^{3}$.

$\rho_{S}$ density of support particle, $\mathrm{kg} / \mathrm{m}^{3}$.

$\rho_{\text {Sm }}$ density of particle-biofilm aggregate, $\mathrm{kg} / \mathrm{m}^{3}$.

$\varphi^{\prime}$ Thiele-type modulus (defined in Equation (15)), dimensionless. 